\title{
Towards a more effective detective
}

\author{
Nina J. Westera*
}

Mark R. Kebbell

ARC Centre of Excellence in Policing and Security (CEPS), Griffith University, Mt Gravatt Campus, Brisbane, Queensland, 4122, Australia n.westera@griffith.edu.au; ph: 0061737351017 m.kebbell@griffith.edu.au; ph: 0061737353353

Becky Milne

Centre of Forensic Interviewing, Institute of Criminal Justice Studies, University of Portsmouth, St. Georges Building,141 High Street, Portsmouth, England PO1 2HY becky.milne@port.ac.uk; ph: 00447801055361

\section{Tracey Green}

Australian Graduate School of Policing and Security, Charles Sturt University, Jam es $\mathrm{H}$ agan Build ing, W agga W agga $\mathrm{C}$ am pus, New South Wales 2678, Australia tgreen@csu.edu.au; Ph: 0061269332651

Key words: Police; detective; criminal investigation; performance.

Word count: 8,959 


\begin{abstract}
The characteristics that detectives believe are required to be an 'effective detective' were explored in this study. A Repertory Grid Technique and Critical Incident Technique were used to explore in detail the views of experienced detectives $(N=30)$ from five different police services in Australia and New Zealand about what makes an effective detective. The findings suggest detectives hold a complex and challenging role that requires eleven key skills. By far the most important factor was communication skills; particularly how to communicate effectively with a variety of people varying from victims and suspects to colleagues and scientific experts. High levels of motivation and thoroughness closely followed communication as essential skills. The implications of these findings for the recruitment, training and management of detectives are discussed.
\end{abstract}


Detectives are entrusted with a serious and onerous role. The investigations they conduct are relied on to identify and convict those guilty of inflicting the most serious of crimes. The stakes are high. Poor investigation may result in dangerous offenders remaining free to commit more harm and even the false conviction of the innocent (Gross et al., 2005). Also important is the way detectives go about their work. Their responsiveness to victims, who are often the most vulnerable members of our society, has been found to effect victim satisfaction with the justice system as a whole (Jordan, 2004; Patterson, 2011). Further, investigations into high profile cases often attract intense public interest and scrutiny, which means that how detectives conduct themselves is likely to impact on public perceptions of police as a whole (Innes, 2003). For these reasons it is essential that the skills, abilities and personal characteristics that combine to make a detective effective are identified. Identifying what these factors are has profound implications for how the detective role is conceptualised and the recruitment, training and management of detectives. Despite the recognised importance of detective work, to date, few empirical studies examine the less tangible skills, abilities and other characteristics that differentiate between those detectives who perform the role effectively and those who do not. The present research attempts to address this gap by exploring the views of experienced detectives in Australia and New Zealand.

Criminal investigation is one of the least researched areas in policing (Brodeur, 2010), but is attracting growing attention as evidenced by the recent special issue of Policing and Society, “Homicide Investigation: International Research and Insights” (2013; Volume 23, Issue 3). The work of Innes (2003) and Brodeur (2010) has helped provide theoretical frameworks for criminal investigation. Acknowledging the complexity of criminal investigation, Innes (2003) focused specifically on homicide by observing five investigations, interviewing investigators and 
reviewing case files (20 complete files and 50 summaries) in England. Innes conceptualised the homicide investigation process as 'the interpretation and communication of information, and the social construction of meaning and understanding that is performed by police' (p.25). Brodeur (2010), who examined 153 homicide investigations and interviewed investigators in Canada, was restricted to examining homicides due to a paucity of information in police files for other crimes. Finding that detectives perceived themselves more as 'courtroom evidence managers' than 'case solvers', Brodeur suggests a theory of criminal investigation must also incorporate a resultorientated focus. Although homicide investigations are usually only a small part of a detective's role, these theoretical frameworks are also likely to extend to other criminal investigations (Innes, 2003).

Rather than examining the criminal investigation process itself, some studies have examined the skills required by detectives to perform this process. These studies tend to focus on whether detective work is best described as an art, craft or science (e.g., Carson, 2009; Innes, 2003; Reppetto, 1978; Tong \& Bowling, 2006). The depiction of detective work as an art aligns closely with the popular conception of a detective having innate, non-concrete, characteristics such as intuition and instinct, that training and education can do little to improve (Reppetto, 1978). In contrast, detective work as a craft represents a more traditional and practical view that experience ‘on the job’ develops craftsmanship such as knowing how to talk to a variety of people or what to include in a case file (Reppetto, 1978). Describing detective work as a science is seen as increasingly relevant with the growing influence of forensic science and investigative psychology (e.g., interviewing, criminal profiling; Reppetto, 1978; Tong \& Bowling, 2006). This approach removes the mystery around detective work and offers an opportunity to take on a more evidence-based approach, grounded in science, to the development of detectives (Tong \& 
Bowling, 2006). Commentators on the art, craft or science debate generally conclude that detectives have a varied and complex role that is best described by the culmination of these three elements (Carson, 2009; Innes, 2003; Reppetto, 1978; Tong \& Bowling, 2006). Two issues arise from this debate. First, more empirical research is required to examine the skills, abilities and characteristics required for a detective to effectively perform this complex and challenging role. Second, as Tong and Bowling (2006) point out, detectives cannot become more professional until this gap is addressed and lays a robust foundation for an evidence-based learning framework (see also Tong, 2009). One way to address this gap is to describe detective work in terms of both the tasks that define the role and the characteristics required to perform the role successfully (Brough \& Smith, 2003).

\section{The tasks of detective work}

Some early studies describe the various tasks involved in the detective role. For example, in the classic Rand study in the United States, Greenwood, Chaiken and Petersilia (1977) examined the effect of the investigative process on case outcomes by surveying 153 police departments, interviewing employees in 29 of those departments and reviewing case files. Their findings suggest that, in contrast to popular perceptions of detectives as 'criminal catchers', the majority of a detective's time is spent documenting cases, and locating and interviewing victims. Other studies expand on the wide variety of tasks conducted by detectives. For example, Maguire, Noaks, Hobbs and Brearley (1991) examined how investigative performance could be measured. Questionnaire responses with 26 detectives and detective sergeants in England suggested that the 'tools of the trade' include legal and local knowledge, communication skills, interviewing skills, preparing case files, cultivating informants, presenting evidence in court, and processing investigative information. Supporting these findings, an earlier study in the United 
States by Cohen and Chaiken (1987) observed investigator behaviour in the workplace and interviewed detectives to develop recommendations for selection and promotion processes. In addition to the skills already mentioned, they found crime scene management, patrol and stakeout were also part of the detective role. Of course, as highlighted by Innes (2002) tasks will vary from case to case, for example, the tasks for a 'self-solver' homicide are likely to be different to 'whodunit' homicide. However, some tasks are likely to be universal across cases.

\section{The required characteristics of a detective}

Arguably more relevant to the recruitment and development of detectives, are not the tasks themselves, but the more generic and less tangible characteristics that define those who perform the role effectively compared to those who do not. In other words, what distinguishes an 'effective' from a 'less effective' detective? Less research has directly examined the characteristics required by individuals to effectively perform the role (for a review of the research in relation to the characteristics required for the core detective skill of investigative interviewing, see Bull, 2013). These characteristics are often referred to in organisational psychology as knowledge, skills, abilities and other personal characteristics (Brough \& Smith, 2003). Of relevance here, two of the earlier studies mentioned found that communication skills were thought to be one of the most important indicators of effective performance (Cohen \& Chaiken, 1987; Maguire et al., 1991). Motivation to work hard, intelligence, persistence, judgment, and initiative were also mentioned in both these studies.

Since this earlier research, more sophisticated job analysis methods have been applied to define effective characteristics for detectives (McGurk, Platton \& Gibson, 1994), senior investigating officers (Smith \& Flanagan, 2000) and volume crime investigators (O’Neill, 2012). McGurk et al. (1994) conducted a job and training needs analysis with four different English 
police forces to inform the development of a national detective training course. In addition to position and task analyses, 15 managers of detectives were interviewed and another 100 detectives completed a written questionnaire. Together the findings suggested four clusters of main skill categories, namely: (1) managing tasks: implementing and controlling; (2) managing information: assisting people and assisting colleagues; (3) dealing with people: collecting, combining, appraising, creative thinking and deciding; (4) effective communication: communication style, writing skills, and personal style. Similar to earlier studies (Cohen \& Chaiken, 1987; Maguire et al., 1991), the authors found that the ability to communicate, which included being personable and approachable, were believed to be most critical to detective work. The authors also noted that 'knowledge' received relatively low ratings, despite the emphasis on this attribute in training regimes at the time. There are several limitations to this study. Many of the skills identified reflect different tasks that detectives perform rather than the generic skills or characteristics an individual requires to perform effectively in the role. For example, 'assisting colleagues' and 'assisting public' in the 'assisting with people' cluster, describe tasks rather than the skills required for effective performance. Also, the interviews were conducted with detectives who were in a supervisory role and thus may have a different perspective to those in a detective role, reducing the generalisability of these findings. In addition, the data were gathered over twenty years ago, so the findings may have become out-dated if what makes an effective detective has changed over this time, for instance, with new legislation and advances in technology.

More recently, in a research paper entitled “The effective detective: Identifying the skills of an effective SIO”, Smith and Flanagan (2000) examined the characteristics associated with being an effective senior investigating officer (SIO; a manager of detectives who also conducts 
investigations into major crime). Semi-structured interviews were conducted with 40 SIO's and other senior ranking detectives. A total of 22 key skills were identified and clustered into the three skill categories of 'investigative ability', 'knowledge levels' and 'management skills'. This study is helpful in informing us about the role of an SIO, but how much it informs us about the detective role itself is questionable. An SIO’s investigative role is to lead major crime (such as homicides) or sensitive investigations, for which they usually have teams of detectives reporting to them. This may require a different skill-set to a detective who may need to conduct investigations more autonomously or perform a variety of roles within a major investigation. Some of the skills described are likely to be similar to those required by detectives, for example those in the investigative ability category, such as appraisal of information, adaptation, and innovative investigative style. Other skills may however differ, because the role of SIO also includes the management of employees. For example, strategic awareness, resource management and staff development, may not be as relevant to basic detective work. Also detectives may require additional skills. For example, communication features more strongly in previous studies that solely examine the detective role (Cohen \& Chaiken, 1987; Maguire et al., 1991; McGurk et al., 1994). This skill may be more important to detectives than SIO’s because detectives may more regularly interview witnesses, suspects and talk to members of the public.

Again in England, O’Neill’s (2012) doctoral dissertation examined the desirable characteristics of volume crime investigators (see also O’Neill \& Milne, 2014). These investigators are a mixture of constables and detectives who investigate crimes such as burglary and vehicle crime. In one study, 61 investigators (most of whom were not trained detectives) rated the characteristics of a successful volume crime investigator using a list of 30 characteristics that were derived from previous research. Communication, motivation, 
commitment, dedication, persistence, initiative and decision-making featured highly. In another study O’Neill asked investigators to identify the five most successful investigators and rate each of them using the same 30 characteristics. He found differences in the ranking of characteristics, for example communication was not ranked as highly, but these findings should be interpreted with caution because all the characteristics scored highly on the 5-point scale used. The role of investigating volume crime is considered a training ground before entering into or completing detective training and going on to investigate more serious crimes and therefore the skills and abilities required may differ from detective work (O’Neill, 2012). These less serious crimes also have specific features, the suspect is often named and not known to the victim, which taken alone, may not provide a broad representation of the characteristics for detective work.

\section{The present study}

The purpose of the present study was to identify the skills, abilities and other characteristics required to be an effective detective with a view to informing the recruitment, training and management of detectives. To empirically examine these issues we conducted semistructured interviews with subject matter experts (Brough \& Smith, 2003), detectives themselves. We used a similar method to Smith and Flanagan (2000) and McGurk et al. (1994). Our first sampling criterion was that all participants must be qualified and experienced detectives. The qualitative nature of the research allowed us to gain a broad representation of views and address the shortcomings of McGurk et al. (1994) thereby enhancing the scope and generalizability of the findings. We therefore chose to interview a variety of detectives from across different policing services; generalist and specialist roles; urban and rural regions; and genders. We also interviewed detective trainers and supervisors, who had all previously performed the detective role, as we believed they could also provide valuable insights. 


\section{Method}

\section{Participants}

Five police services in Australia and New Zealand agreed to participate in this study. A contact person in each service was asked to nominate qualified detectives, from a variety of roles and mixture of genders, who met the sampling criteria for this study. All detectives nominated agreed to participate in an interview with the first researcher during their work time $(N=30)$. Interviews were conducted in person except for one interview with a detective working in a remote region that was conducted on the telephone for accessibility.

The detectives were from the Australian Federal Police, Queensland Police Service, New Zealand Police, Western Australia Police, and New South Wales Police Force. The mean age was 39.60 years $(S D=4.72) ; 19$ were male $(63.3 \%)$ and 11 were female $(36.7 \%)$. The detectives were generally very experienced with time served in police ranging from 6 to 31 years ( $M=15.43$ years, $S D=5.01)$ and time served in the detective branch ranging from 4 to 25 years $(M=10.47$ years, $S D=4.90)$. They were from a mixture of metropolitan $(N=24)$ and rural areas $(N=6)$; and a variety of roles including specialist (child protection, sex crime, fraud, homicide and organised crime; $N=15)$, general $(N=9)$ and detectives who were now in a detective training role $(N=6)$. Half the sample were solely detectives $(N=15)$, and the remaining, who had all previously worked as detectives, held the equivalent rank of detective sergeant (first tier managers; $N=11$ ) and detective senior sergeant (second tier managers; $N=4$ ).

\section{Data collection and analysis}

Each participant was interviewed for approximately an hour using three different methods. The amount of time spent on each method varied for each participant. Using multiple methods to examine the same phenomena allows for triangulation of the data, where a 
convergence of findings can add to confidence in the validity of the findings (Jick, 1979). Another benefit of this approach is the deficiencies of one method can be counter-balanced by the strengths of another, allowing the collection of more holistic and contextually-rich qualitative data.

\section{Repertory grid technique}

The Repertory Grid Technique (RGT) is a flexible method that can help to identify less observable constructs and concisely articulate what makes an individual, in a certain role, effective (Brough \& Smith, 2003). Derived from Kelly’s (1955) personal construct theory, the RGT examines how respondents try to construe the world or their implicit theoretical beliefs about different constructs (Fransella, Bell, \& Bannister, 2004). Kelly (1955) suggests it is helpful to conceptualise the belief systems as sets of linked bipolar constructs where the positive is grounded against a negative opposite. Hence, the RGT involves first defining the elements, for example, in the present study the elements are what respondents perceive as effective in contrast to less effective detectives. Then respondents are asked to identify the positive and negative constructs that distinguish one element from another. For example, constructs that differentiate effective from less effective detectives may include - hardworking-lazy. In the present study participants were asked to identify, but not name, two detectives that they thought were effective in the role (referred to as ' $A$ ' and 'B') and two detectives that thought were less effective in the role (referred to as 'C' and ' $\mathrm{D}$ '). The researcher selected three of the four nominated detectives and asked the participant to compare how the skills, abilities and other characteristics of two detectives were similar and hence different from the third. The process was repeated until the participant had exhausted all constructs for all combinations of the four different detectives nominated. The RGT was used first in the interview because it requires high levels of effort from 
both the participant and the interviewer (Fransella et al., 2004). Another limitation of the RGT is that the interviewer may have a different understanding of the labels given by the participant to each construct (Fransella et al., 2004). To address this problem, the participant was also asked to describe what each construct meant to him or her.

\section{Critical incident technique}

Whereas the RGT identifies an individual's characteristics, the Critical Incident Technique (CIT) explores how performed acts relate to outcomes in an incident (Flanagan, 1954). Thus, CIT can help to identify specific observable behaviours that are perceived as central to forming a functional description of detective work. Participants were asked to describe an incident that demonstrated a detective displaying either good or bad practice, identify what was good or bad about the practice, and explain their perceived consequences of the practice. The process was repeated with a second incident so that an example of both good and bad practice was obtained. The CIT was used to provide details about observed behaviours that contribute to good or poor performance and how that affected the outcome. The CIT is limited by a participant's ability to remember a specific event and relies on the attributions of that participant about how an outcome was achieved. Although these attributions are subjective, the CIT still helps us to understand what detectives perceive are important factors in achieving effective outcomes.

\section{Semi-structured interview}

In the semi-structured interview participants were asked 'what are the three most critical skills required by an effective detective?' and to describe each of these skills. This method was used to gain a direct understanding of what participants perceived as effective skills. 


\section{Results}

From the detailed hand-written notes taken during the interviews, we systematically analysed the themes of detectives’ responses regarding the skills, abilities and other characteristics required for an effective detective. A bottom-up approach was used to derive categories from the themes of detectives' responses rather than pre-existing constructs (Gifford, 1998). For each of the three interview methods used (RGT, CIT and semi-structured interview), the detectives' responses were separately collated and analysed. Despite the variety of age, gender, role and location of the detectives interviewed, the analysis found that the themes generated by each of the three interview methods used were remarkably consistent. Thus, for ease of comparison and interpretation, the same 'skill categories ${ }^{1}$ are used to report on the findings of each interview method.

The first researcher manually analysed all the detectives’ responses. Another researcher coded a random selection of $20 \%$ of all RGT responses. Inter-rater reliability was calculated to determine consistency between the coders. The analysis found that the coders agreed $89 \%$ of the time. Disagreements in coding were discussed and resolved.

\section{Repertory Grid Technique}

Each of the thirty detectives compared the characteristics, skills and abilities of two effective and two less effective detectives that they knew. A total of 276 effective-less effective constructs were identified. As listed in Table 1, a content analysis of the constructs identified eleven 'skill categories' perceived to differentiate effective from less effective detectives. ‘Communication’ was overwhelming the most frequently cited skill category followed by 'motivation'. 'thoroughness', 'management' and 'decision-making' which were also in the top five skill categories. ‘Knowledge’, ‘leadership’, ‘tenacity’, ‘experience’, ‘resilience’, and 
'teamwork' made up the remainder of the eleven categories. Four constructs did not fit into any of the eleven categories and were coded 'miscellaneous'.

[Insert Table 1 near here]

Within the most common category, communication, constructs for effectiveness also included personable, approachable, good with people, rapport, empathy, articulate, humility, non-judgemental and written communication skills. Opposites denoting less effective communication included not personable, inarticulate, no empathy, not caring, judgemental and standoffish. In the second most frequently cited category, motivation, constructs for effectiveness also included work ethic, driven, committed, dedicated, passionate, enthusiastic, conscientious, hardworking, pride in work and can do attitude. Less effective constructs included lazy, complacent, no passion, doesn’t care, no work ethic, disinterested, blasé, directionless and disengaged.

For the third most frequently cited skill category, thoroughness, effective constructs also included attention to detail and methodical. Opposites included sloppy, lack of attention to detail and less structured. The next most frequently cited skill categories were management and decision-making. Management also included organised, plans and prioritises. Opposites included disorganised and inefficient. Decision-making also included decisive and considers all options. Opposites included inability to make decisions and poor judgment.

The sixth most frequently cited skill was knowledge. Also included in this category was knowledge of the law and investigative knowledge. Opposites were not knowledgeable and ignorance of the law. Leadership was the seventh most cited. Leadership constructs also included leads by example and role model. Opposites included no leadership and follower. Experience 
was also frequently cited and included experience as a detective and experience before joining the detective branch. Opposites included inexperience and thinks is experienced but isn't.

Tenacity and resilience were both frequently cited. Tenacity also included persistent and determined. Opposites included gives up easily and doesn’t push it. The resilience category included resilience to perform effectively day to day in a stressful working environment and also long-term resilience to ensure emotional wellbeing. Also included were well-rounded life and sense of humour. Opposites included influenced by work environment, and muddle work and life. A frequently cited skill, teamwork, included team player and open to feedback. Opposites included lack of teamwork and no respect of peers. Notably, when describing 'communication' detectives often incorporated an ability to communicate with colleagues, suggesting the frequencies reported here may not fully represent the importance of teamwork.

\section{Critical Incident Technique}

Each participant described one incident demonstrating good and another bad investigative practice and how that practice affected the outcome, resulting in thirty examples of each. A total of 103 skills and abilities that contributed to good practice were identified, and 72 skills and abilities that contributed to bad practice. As mentioned, these examples were content analysed and classified into the eleven skill categories previously identified. The number of participants that cited one or more items in each skill category was calculated and is listed on Table 1.

The findings support and extend the RGT findings. Effective communication was again the standout skill category and most frequently cited as contributing to both good and bad practice. One participant described an example of good practice explaining how a detective had communicated with a family member of a homicide victim in a caring and open-minded way, which resulted in the same person later admitting that they had committed the murder. In an 
example of bad practice an incident was described where a detective was judgmental and closed minded when interviewing a victim of sexual assault, which resulted in her refusing to make a complaint. In contrast to the RGT findings where motivation featured strongly, decision-making was the second most cited skill category, far outweighing all other skill categories. Thoroughness, motivation, and management were also frequently cited as contributing to good and bad practice. Experience, resilience and tenacity were next most common. Knowledge, leadership, and teamwork featured least commonly. Interestingly, resilience was proportionately cited more frequently in examples of good practice than bad practice and tenacity never featured in examples of bad practice, suggesting that these skill categories are associated with positive performance rather than poor performance.

\section{Top three skills}

Participants were asked to identify and describe the three most critical skills for being an effective detective. A total of 44 critical skills were identified, content analysed and again classified using the eleven skill categories previously identified. Two responses were coded as miscellaneous. The number of participants that cited one or more items in each skill category was calculated and is listed on Table 1 . This table also includes the overall percentage of participants that cited each skill category at some stage during the interview. How detectives describe each skill, ability or other characteristic helps to more clearly define each skill category and is displayed in Table 2.

[Insert Table 2 near here]

\section{Discussion}

Our findings suggest that the detective role is complex and challenging, and requires a combination of diverse skills. As such, we identified eleven main categories of skills, abilities 
and other characteristics that are perceived by the respondents as integral to effective performance. The skills identified are sometimes orthogonal and may even be opposites. For example, it is desirable for a detective to be personable and approachable as well as methodical and attentive to detail. It is likely to be challenging to find or develop this array of skills in one individual. We will now discuss these 'skill categories' starting with the two skills identified as most important - communication and motivation.

Communication was the most critical skill by far. All participants mentioned communication at some stage during the interview and it was the most frequently cited skill category with each of the three interview methods used. This finding is consistent with other studies which have also found communication is essential to effectiveness (Cohen \& Chaiken, 1987; Maguire et al., 1991; McGurk et al., 1994; O’Neill, 2012). Further, previous studies also suggest that most crimes are solved due to information from the public (Brodeur, 2010; Ericson, 1993; Greenwood et al, 1977), and investigators are aware that this is the case (Kebbell \& Milne, 1998; Kebbell \& Wagstaff, 1997). If, as suggested by Innes (2003), information production is central to criminal investigation, communication is the means by which detectives provide this lifeblood.

Detectives' description of communication, as the flexibility to talk to anyone, anywhere, at any time and for any purpose, fits with Hobb’s (1988) notion of the entrepreneurial nature of detective work. The types of communication interactions described by detectives were diverse, and often emotional and high-stake. Perhaps like few other jobs, detective work demands that the individual communicates with such a variety of people and in complex and varied circumstances. For example, a detective may be required to take an initial complaint from a member of the public, and interview victims, witnesses, and suspects related to the same case. They must also 
communicate with others in the justice system such as fellow detectives, uniformed officers, their supervisors, medical professionals, defence and prosecution lawyers, judges and jurors. The circumstances of each interaction also vary, for instance, interviewing a victim may range from communicating with someone who is traumatised but forthcoming with information to someone who is hostile towards police and reticent to talk. Interviewing a suspect may range from communicating with an aggressive individual with a mental health problem to a co-operative, but upset suspect who wants to reveal all. Interactions are also likely to involve people from groups that are over-represented in the crime statistics and different to detectives themselves. For example, the Australian Crime Survey in 2011 found that the largest proportion of police detainees were male and had not completed school, and 15-19 year olds were the age group that had the highest rate of offending (Australian Institute of Criminology, 2012). In addition to faceto-face interactions, detectives described the importance of generating a high standard of prosecution case files, which supports Brodeur's (2010) findings about the importance of postcharge activities. A diverse skill-set is likely required of detectives to cater for this range of people and scenarios.

How is effective communication defined in these challenging contexts? Research into investigative interviewing may help to define effective communication, but even this extensive body of research pays little attention to how to adapt to meet the diverse needs of different individuals detectives encounter (e.g., Bull, 2013). Some generic features may apply to all communications, identifying what these are could help more clearly define effectiveness. How detectives describe effective communication, adopting an empathetic, respectful and nonjudgemental approach, may be the key. More research is required, but studies in interviewing complainants and suspects support a non-judgemental approach (e.g., Kebbell, Alison, \& Hurren, 
2008; Kebbell, Allison, Hurren, \& Mazerolle, 2010; Patterson, 2011). This is also consistent with the principles of procedural justice that highlight the need for fairness and engaging the individual in the process (see Mazerolle et al., 2013).

Interestingly, detectives may be in the ideal position to learn what effective communication in a policing context involves. Unlike many other policing roles, they are typically exposed to both the short and long-term consequences of their communication interactions. For example, a detective may have contact with a witness early in an investigation and, months or years later, they may need to persuade and motivate the witness to give evidence in court. First impressions are highly influential and the longevity of this contact is distinct from one-off interaction more typical in other policing contexts. Detectives' comments in the present study, that someone who was a suspect one day may be a witness the next, support the importance of establishing an on-going relationship with the people they deal with. As a result detectives receive feedback about the success of the approaches they use, which may create an ideal condition for effective learning (Ericsson, Krampe, \& Tesch-Römer, 1993). Yet, even if detectives do understand the importance of skills like rapport, this does not mean they use these skills effectively in practice. For example, an analysis of 142 interviews with suspects found that many fraud investigators were often poor at building, and especially at maintaining, rapport during the interview (Walsh \& Bull, 2012). In a review of what is believed and what is actually known about effective investigative interviewing, Bull (2013) also highlights the importance of balancing a humane approach with remaining sceptical. Whatever the case, engendering the ability to communicate with a variety of people appears to be vital to the selection and training of detectives. 
Detectives perceived that being highly motivated was also essential to effective performance. This finding is supported by previous research (Cohen \& Chaiken, 1987; Maguire et al., 1991; McGurk et al., 1994) and the 'hard-working' culture that is symbolic to detective work (Innes, 2003). Detectives in the present study reported that they are motivated by a desire for justice, to seek the truth and to do what is right for victims. This supports Brodeur's (2010) 'pragmatic' theory that detectives are results-orientated, but also the findings of Brookman and Innes (2013) that suggests broader outcomes, such as community impact, are also measures of investigative success. More research is required to validate what motivates a detective, but the very nature of the detective role may fuel the motivation to see justice done. Unlike other professions in the justice system, detectives deal with those who are effected by and commit crime near crisis point. Alleged offenders are often intoxicated, stressed and aggressive, and victims are often suffering from extreme psychological and physical trauma. Facing the emotional extremes of this raw face of crime may drive detectives to see justice done, especially if the desired empathetic approach is adopted. A risk of course, is that detectives are too influenced by these experiences and resort to emotionally driven decision-making that is more prone to bias (Chaiken, Liberman, \& Eagly, 1989; Nickerson, 1998). On the other hand, if motivation is important, it is these very experiences that may drive detectives to perform effectively in what may be an otherwise thankless but demanding role. Following communication and motivation, the next three most desirable skill categories for a detective thoroughness, decision-making and management - are likely to form the basis for an effective investigative method. Detectives described the importance of applying these skills across all investigative tasks from planning an investigation, to examining a scene, interviewing, preparing a prosecution file and dealing with a high investigative workload. Previous studies into the 
detective role have also identified the importance of decision-making and management in the complex and dynamic criminal investigation process (Cohen \& Chaiken, 1987; Innes, 2003; Maguire et al., 1991; McGurk et al., 1994), but thoroughness has received less explicit attention. The importance of thoroughness is consistent with the purpose of a detective to gather information from a variety of sources in a manner that meets the requirements of the criminal justice system (Innes, 2003) and produces effective case outcomes in terms of both conviction and adherence to proper procedure (Brodeur, 2010; Brookman \& Innes, 2013). Thoroughness may be more easily defined and measured than other key skills because detectives are required to document their work. For example, a simple way to examine thoroughness is to review case files against a prescribed measure that incorporates legal and investigative requirements. Indeed studies that examine investigative performance by reviewing prosecution case files, such as Greenwood et al. (1977), generally examine how thorough detectives are in meeting requirements set by legal practitioners. Although it is important to note that not all cases result in prosecution so these types of measures do not provide a complete picture of thoroughness.

Four of the remaining skill categories knowledge, experience, tenacity and teamwork are also validated by previous studies (Cohen \& Chaiken, 1987; Maguire et al., 1991; McGurk et al., 1994; O’Neill, 2012). Although there are some slight variations, likely due to the different categorisation systems used (Smith \& Flanagan, 2000). The other two categories, leadership and resilience, have received little attention. Each one of these six skill categories warrants further discussion, but for interests of brevity we will only provide a summary here. Experience as a police officer and as an investigator, as well as knowledge were perceived to lay the foundation for effective performance. This finding is unsurprising given that role specific knowledge is a requirement for any profession. Experience, in particular learning from prior experiences, is a 
core component of developing expertise more generally and aligns with the common perception of detective work as a craft (Ericsson et al., 1993; Hattie \& Timperley, 2007; Innes, 2003; Reppetto, 1978). Although to be effective, learning from experience requires expert feedback, which may or may not be present in detective learning programmes (Ericsson, et al., 1993).

Teamwork and leadership were also prominently cited skill categories. The need for these skills is likely to be closely linked to communication and suggest that the ability to work in a team is a core component of detective work. The importance of leadership found in the present study also suggests that detectives not only need the ability to adapt to perform specific roles within the team, but also to take charge and lead when required. For example, leadership may be required when a detectives is in charge of their own investigation whereas teamwork may be required when working on a major investigation such as a homicide. Further emphasising the complexity and demanding nature of the role, tenacity and resilience were also identified as important characteristics. Unlike the ability to communicate and work in a team, these skill categories are likely to be more internally driven.

\section{Limitations and future directions}

Before discussing the implications of the findings further, it is important to note the limitations of the present study. The interview methods used produce subjective responses from detectives about what they perceive as effective characteristics, which may differ from what actually is effective. For example, in one study O’Neill (2012) used objective measures of success (e.g. detection rates) to identify and compare 30 'high performing' and 30 'low performing' investigators. O’Neill found no differences between these two groups for psychological measures of personality type, critical thinking or empathy, despite investigators previously identifying these characteristics as important to success. 
The detectives interviewed in the present study were generally very experienced, averaging 15 years in police, so they may unduly emphasise the importance of experience or hold different views from younger generations. Half the group were detectives in a supervisory role, which may influence their perceptions of what is important, however the consistency of the findings suggests there is agreement about the characteristics required for the role. On the other hand, the use of experienced detectives and their immediate supervisors is also a strength of this study because, as part of their everyday work, they are in the best position to know the requirements of the role. Further, the mixture of detectives sampled from different police services allowed us to obtain a wide variety of viewpoints about the generic characteristics required for detective work. If biases were operating, we would expect less uniformity in responses. Whatever the case, the findings do indicate what detectives themselves perceive as valuable to performing the role and add to our understanding of detective culture (see Innes, 2003). Future research should explore the validity of detectives’ views and how the characteristics vary for more specialist roles. For example, investigators of internet child abuse may need specific types of communication skills to perform effectively when dealing with child sex offenders in an online environment.

The debate about the usefulness of conceptualising detective work as an art, craft or science will be left to others. However, the findings of the present study support the views of many commentators that the role is complex and does not fit clearly into any one of these categories, but rather is a combination of them all (e.g., Innes, 2003; Reppetto, 1978). If professionalism is the goal, as proposed by Tong and Bowling (2006), we suggest that it is useful to extend the approach of the present study and further examine the tasks and characteristics required to perform the role effectively. This approach provides a platform for job design and 
evaluation; job descriptions and recruitment criteria; training and on-going development; and performance appraisal (Brough \& Smith, 2003). As mentioned, previous studies have already identified the tasks, such as planning investigations, interviewing suspects and witnesses, examining crime scenes and gathering evidence, cultivating informants, preparing case files and giving evidence (Cohen \& Chaiken, 1987; Greenwood et. al, 1977; Maguire et al., 1991). Matching these tasks with the eleven skill categories identified in the present study provides a starting point for the development of a robust evidence-based learning framework. Future research could use these skill categories to determine how competency may be measured, explore to what extent these skill categories are learnable, and to understand how they may be developed.

\section{Implications for recruitment, training and management}

The findings of this research can assist with the development of evidence-based policy and practice for the selection and development of detectives. Recruiting those who already have the correct skills and characteristics, is the simplest way to ensure detectives have those requisite characteristics required to do the job effectively. Communication skills are fundamental but difficult to learn (e.g., Milne \& Bull, 1999; Powell, Fisher, \& Wright, 2005). Interpersonal communication skills, motivation and thoroughness may provide useful selection criteria. It is beyond the scope of this article, but a closer examination of how, if it is possible, to validly measure these core characteristics required for detective work. Psychological testing for characteristics that are more stable and personality related may also assist. For example, conscientiousness on the five-factor model for personality is likely to indicate a tendency for thoroughness (see Digman, 1990; Ozer \& Reise, 1994; see Bull 2013 for a review see Bull 2013 for a review of current literature on personality factors and investigative interviewing). 
Training programmes for detectives should include both knowledge acquisition and skill development. McGurk et al. (1994) has previously criticised the over-emphasis of legal knowledge in police training programmes at the expense of other training needs. However the present study suggests that knowledge of the law is a core requirement that needs to be addressed alongside knowledge of investigative method. Developing investigative knowledge is likely to incorporate learning about the tasks detectives conduct (e.g. interviewing, crime scene examination) and how those tasks are conducted effectively through the application of the characteristics identified in the present study (e.g. effective communication, thoroughness, management). This knowledge is the foundation for skill development and is likely to include underlying principles and processes involved. For example, the findings of the present study combined with that of other studies (e.g., Bull, 2013; Powell et al., 2005), suggest that for the knowledge underpinning effective communication, detectives may need to know about: the scientific basis for the methods used, the value of adopting a non-judgmental approach, and the process of how to elicit information from a variety of people and scenarios. Knowledge could include strategies and tools that are useful for developing core skills. For example, training in information analysis methods may assist with learning to apply thoroughness to investigative work.

Once foundation knowledge is learnt, a wealth of research indicates how to acquire and develop skills (see Smets \& Rispens, 2014). Practical scenario based training that incorporates spaced learning over time, gradual progression in complexity, and practice accompanied by immediate expert feedback are all important (Ericsson et al., 1993; Hattie \& Timperley, 2007; Powell, Fisher, \& Wright, 2005). Indeed, some police services have already adopted training programmes that fit this approach for investigations in general (e.g. Professionalising 
Investigative Programme in England; National Centre for Policing Excellence, 2006) or interviewing (e.g., PEACE interviewing in England and Wales, and New Zealand; Clarke \& Milne, 2001; Schollum, 2006).

However detectives are trained, the work is not prescriptive, thus central to any training is encouraging autonomy and a flexible approach that enables detectives to respond to the wide variety of challenging scenarios they are likely to come across in the field. In this regard, the management of detectives should include consideration of how to expose them to a variety of experiences. Not only does this involve time in the role, or different aspects of detective work, but also exposing detectives to increasing complex, but achievable, challenges that are ideal for learning and expert feedback (e.g., Ericsson et al., 1993). Finally, in addition to the internal motivators of detectives, exploring what organisational factors motivate and de-motivate detectives may assist with maintaining effectiveness. Studies such as Innes (2002) who examined how legal, organisational and investigative factors may influence actions performed by detectives may be helpful. Exploration of factors identified as effecting job satisfaction and retention in more general policing research, such as supervisor support and organisational recognition may also be appropriate (Brough, 2005; Brough \& Frame, 2004; Chan \& Doran, 2009). Clearly, motivating detectives and not demotivating them should be a major goal of policing organisations.

\section{Conclusion}

We now know that detectives identify communication skills, motivation and thoroughness as the most important attributes of an effective detective. The challenge is now for academics and police to work together to ensure that detectives with these attributes are recruited, trained and retained. 


\section{Acknowledgements}

This research was conducted at the ARC Centre of Excellence in Policing and Security with funding from the Australian Research Council (SR07000002). The authors wish to acknowledge the Australian Federal Police, New South Wales Police Force, New Zealand Police, Queensland Police Service and Western Australian Police who made this research happen and the detectives from these agencies who gave their valuable time to participate in this study. Finally to the anonymous reviewers for this journal who provided us with valuable feedback. 


\section{References}

Brodeur, J.P. (2010). The policing web. New York: Oxford University Press.

Brookman, F., \& Innes, M. (2013). The problem of success: What is a 'good' homicide investigation? Policing \& Society, 23(3), 292-310.

Brough, P. (2005). A Comparative Investigation of the Predictors of Work-related Psychological Well-being within Police, Fire and Ambulance Workers. New Zealand Journal of Psychology, 34(2), 127-134.

Brough, P., \& Frame, R. (2004). Predicting Police Job Satisfaction and Turnover Intentions: The role of social support and police organisational variables. New Zealand Journal of Psychology, 33(1), 8-16.

Brough, P., \& Smith, M. (2003). Job analysis. In: M. P. O'Driscoll, P. J. Taylor \& T. Kalliath, eds. Organisational psychology in Australia and New Zealand. Melbourne: Oxford University Press, 11-30.

Bull, R. (2013). What is ‘believed’ or actually ‘known’ about characteristics that may contribute to being a good/effective interviewer? Investigative Interviewing Research and Practice, 128-143.

Carson, D. (2009). Detecting, developing and disseminating detectives' 'creative' skills. Policing and Society, 19(3), 216-225.

Chaiken, S., Liberman, A., \& Eagly, A. H. (1989). Heuristic and systematic information processing within and beyond the persuasion context. In: J. S. Uleman \& J. A. Bargh, eds. Unintended thought. New York: Guilford Press, 212-252.

Chan, D., \& Doran, S. (2009). Staying in the job: Job satisfaction among mid-career police officers. Policing, 3(1), 66-77. 
Clarke, C., \& Milne, R. (2001). National evaluation of the PEACE investigative interviewing course. Police Research Award Scheme: Report No. PRAS/149. Institute of Criminal Justice Studies, University of Portsmouth.

Cohen, L., \& Chaiken, J. (1987). Investigators who perform well. Washington, D.C.: National Institute of Justice.

Digman, J. M. (1990). Personality structure: Emergence of the five-factor model. Annual Review of Psychology, 41(1), 417-440.

Ericson, R. (1993). Making crime. Toronto: University of Toronto Press.

Ericsson, K. A., Krampe, R. T., \& Tesch-Römer, C. (1993). The role of deliberate practice in the acquisition of expert performance. Psychological Review, 100(3), 363-406.

Flanagan, J. C. (1954). The critical incident technique. Psychological Bulletin, 51, 327-358.

Fransella, F., Bell, R. C., \& Bannister, D. (2004). A manual for repertory grid technique. 2nd ed. Chichester: John Wiley and Sons.

Gifford, S. (1998). Analysis of non-numerical research. In: C. Kerr, R. Taylor \& G. Heard eds. Handbook of public health methods. New York: McCraw-Hill, 543-554.

Greenwood, P. W., Chaiken, J. M., \& Petersilia, J. (1977). The Criminal Investigation Process. Massachusetts: The Rand Corporation.

Gross, S. R., Jacoby, K., Matheson, D. J., Montgomery, N., \& Patil, S. (2005). Exonerations in the United States 1989 through 2003. Journal of Criminal Law \& Criminology, 95(2), 523-560.

Hattie, J., \& Timperley, H. (2007). The power of feedback. Review of Educational Research, 77(1), 81-112. 
Hobbs, D., (1998). Doing the business: Entrepreneurship, detectives and the working class in the East End of London. Oxford: Oxford University Press.

Innes, M. (2002). The 'process structures' of police homicide investigations. British Journal of Criminology, 42, 669-688.

Innes, M. (2003). Investigating murder: Detective work and the police response to criminal homicide. Oxford: Oxford University Press.

Institute, A. C. (2012). Australian crime: Facts and figures 2011. Canberra: Australian Institute of Criminology.

Jick, T. D. (1979). Mixing qualitative and quantitative methods: Triangulation in action. Administrative Science Quarterly, 24(4), 602-611.

Jordan, J. (2004). The word of a woman: Police, rape and belief. Basingstoke: Palgrave MacMillan.

Kebbell, M. R., Alison, L. J., \& Hurren, E. J. (2008). Sex offenders' perceptions of the effectiveness and fairness of humanity, dominance and understanding of cognitive distortions in police interviews: a vignette study. Psychology, Crime \& Law, 14, 435-449.

Kebbell, M. R., Allison, L. J., Hurren, E. J., \& Mazerolle, P. (2010). How do sex offenders think police should interview to elicit confessions from sex offenders? Psychology, Crime \& Law, 16, 567-584.

Kebbell, M. R., \& Milne, R. (1998). Police officers' perceptions of eyewitness performance in forensic investigations. Journal of Social Psychology, 138, 323-339.

Kebbell, M. R., \& Wagstaff, G. F. (1997). Why do the police interview eyewitnesses? Interview objectives and the evaluation of eyewitness performance. The Journal of Psychology, 131, 595-601. 
Kelly, G. A. (1955). The psychology of personal constructs. New York: Norton.

Maguire, M., Noaks, L., Hobbs, R., \& Brearley, N. (1991). Assessing investigative performance. Cardiff: University of Wales.

Mazerolle, L., Bennett, S., Davis, J., Sargeant, E., \& Manning, M. (2013). Legitimacy and policing [online]. The Campbell Collaboration Library of Systematic Reviews, 1. Available from: http://www. campbellcollaboration.org/library.php [Accessed 3 March 2013].

McGurk, B., Platton, T., \& Gibson, R. L. (1994). Detectives: A job and training needs analysis. In: G. M. Stephenson \& N. K. Clark, eds. Rights and risks: The application of forensic psychology. Leicester: British Psychological Society, 24-31.

Milne, R., \& Bull, R. (1999). Investigative interviewing: psychology and practice. Chichester: Wiley.

National Centre for Policing Excellence. (2006). Implementation support plan for the Professionalising Investigation Programme (PIP) [online]. College of Policing. Available from: http://www.college.police.uk/en/docs/PIP_ISP_Final.pdf [Accessed 11 March 2013].

Nickerson, R. F. (1998). Confirmation bias: A ubiquitous phenomenon in many guises. Review of General Psychology, 2(2), 175-220.

O’Neill, M. (2012). What makes a successful volume crime investigator. Unpublished doctoral dissertation: University of Portsmouth.

O’Neill, M., \& Milne, R. (2014). Success within criminal investigations: Is communication still a key component? In R.Bull (Ed.), Investigative interviewing. New York: Springer, 123146. 
Ozer, D. J., \& Reise, S. P. (1994). Personality assessment. Annual Review of Psychology, 45, 357-357.

Patterson, D. (2011). The impact of detectives' manner of questioning on rape victims' disclosure. Violence Against Women, 17(11), 1349-1373.

Policing and Society,

Powell, M. B., Fisher, R. P., \& Wright, R. (2005). Investigative interviewing. In: N. Brewer \& K. Williams, eds. Psychology and law: An empirical perspective. New York: Guilford, 1142.

Reppetto, T. A. (1978). The detective task: State of the art, science, craft? Police Studies: International Review of Police Development, 5, 5-10.

Schollum, M. (2006). Investigative interviewing: The recommendations. Wellington: New Zealand Police.

Smets, L., \& Rispens, I. (2014). Investigative interviewing and training: The investigative interviewer apprentice. In R.Bull (Ed.), Investigative interviewing. New York: Springer, 147-166.

Smith, N., \& Flanagan, C. (2000). The effective detective: Identifying the skills of an effective SIO. London: Home Office.

Tong, S. (2009). Professionalising investigation. In: S. Tong, R. P. Bryant \& M. A. H. Horvath, eds. Understanding criminal investigation. Chichester: Wiley-Blackwell, 197-216.

Tong, S., \& Bowling, B. (2006). Art, craft and science of detective work. The Police Journal, 79, 323-329. 
Walsh, D., \& Bull, R. (2012). Examining rapport in investigative interviews with suspects: Does its building and maintenance work? Journal of Police and Criminal Psychology, 27, 7384. 


\section{Footnotes}

${ }^{*}$ Corresponding author.

${ }^{1}$ We use the term 'skill category' for ease of reading, although we note that some of these 'skill categories’ may be better described as abilities or other characteristics. 
Table 1

Overall rankings and frequencies of eleven skill categories for an effective detective from Repertory Grid Technique, Critical Incident Technique and semi-structured interview

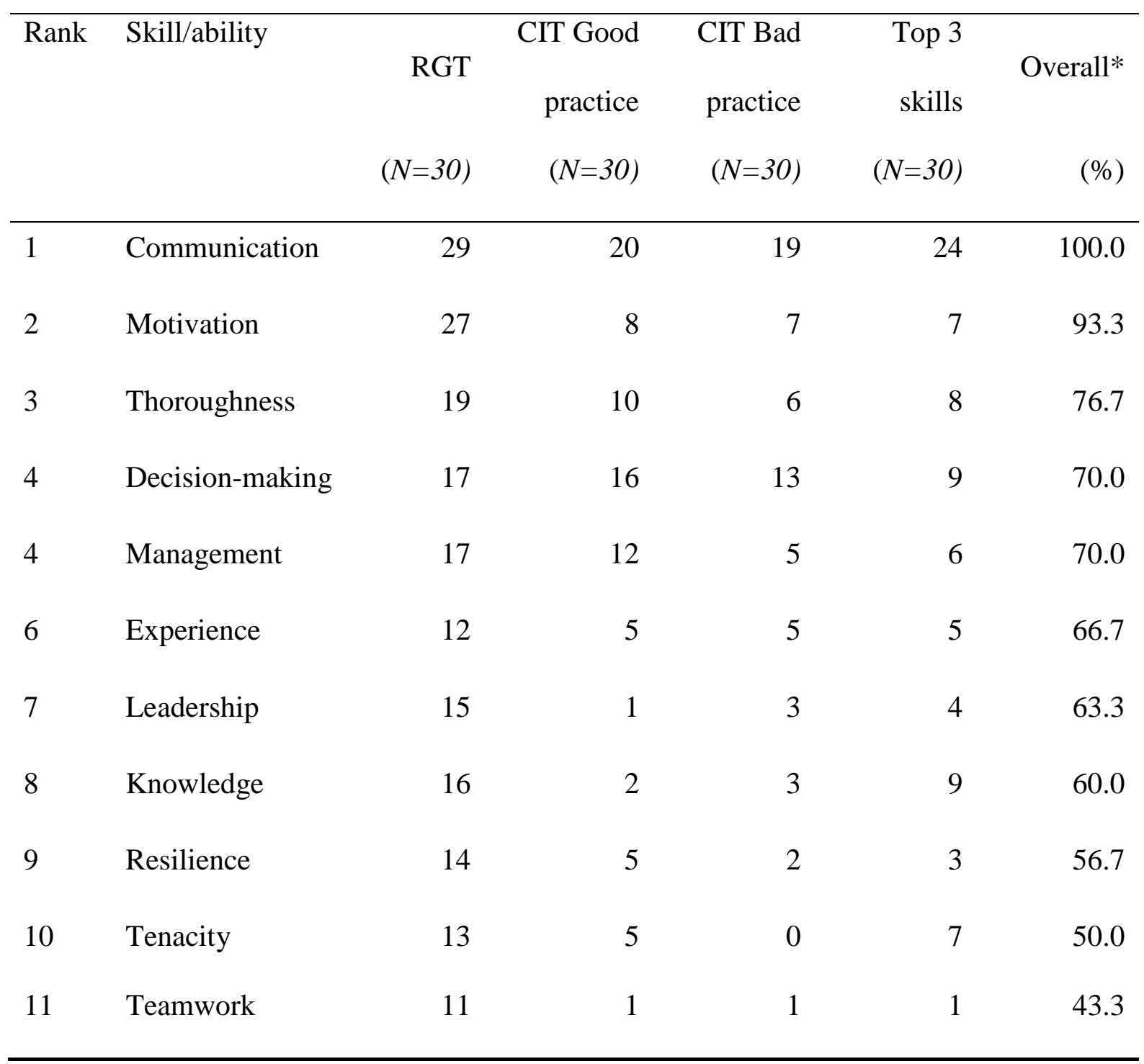

*Percentage of participants who identified skill category at any phase of the interview.

[Insert Running title of $<72$ characters] 
Table 2

Description of the eleven skill categories required for an effective detective

\begin{tabular}{|c|c|}
\hline Skill category & Description \\
\hline Communication & $\begin{array}{l}\text { Clearly articulates with influence what is required to all varieties of } \\
\text { people, regardless of their background or context, to achieve desired } \\
\text { outcome. Establishes rapport, shows empathy, is flexible and } \\
\text { personable, treats people non-judgmentally and with respect, } \\
\text { establishes relationships of trust, actively listens, questions and seeks } \\
\text { clarification, is patient and controlled, and gives confidence to } \\
\text { respondents. Communicates well orally for tasks such as interviewing, } \\
\text { speaking to informants, conducting briefings, giving evidence; and } \\
\text { produces a high standard of written communication for prosecution } \\
\text { files. }\end{array}$ \\
\hline Motivation & $\begin{array}{l}\text { Is genuinely passionate about the role, committed, goal driven with a } \\
\text { strong work ethic, has a 'can do' attitude, and is driven by a desire to } \\
\text { do what is right for victims, seek the truth and see justice done. }\end{array}$ \\
\hline Thoroughness & $\begin{array}{l}\text { Pays attention to detail and methodically attends to all aspects of } \\
\text { detective work including how investigations are conducted, } \\
\text { interviewing, scene examinations, and file preparation. }\end{array}$ \\
\hline $\begin{array}{l}\text { Decision- } \\
\text { making }\end{array}$ & $\begin{array}{l}\text { Analyses information to make clear and logical decisions under } \\
\text { pressure while remaining open-minded and flexible to respond to } \\
\text { unfolding scenarios. Thinks about the big picture, critically, and } \\
\text { outside of the square, and takes calculated risks. }\end{array}$ \\
\hline Management & $\begin{array}{l}\text { Uses organisational skills to plan, prioritise and conduct investigations; } \\
\text { manages a high investigative workload; and acquires and uses } \\
\text { resources effectively including managing people and delegating where } \\
\text { appropriate. }\end{array}$ \\
\hline Experience & $\begin{array}{l}\text { Has learnt from life experience and working in a variety of policing } \\
\text { roles including uniform, rural and investigative. Applies this }\end{array}$ \\
\hline
\end{tabular}

[Insert Running title of $<72$ characters] 
experience to achieve effective outcomes through lessons learned.

\begin{tabular}{|c|c|}
\hline Leadership & $\begin{array}{l}\text { Engenders confidence in other officers through decisive action and } \\
\text { clear communication, leads by example, and has the self-assurance to } \\
\text { seek advice and change the investigative approach when appropriate. }\end{array}$ \\
\hline Knowledge & $\begin{array}{l}\text { Has legal and investigative knowledge, a willingness to learn and seek } \\
\text { new knowledge, and applies knowledge effectively. }\end{array}$ \\
\hline Resilience & $\begin{array}{l}\text { Copes emotionally under the extensive professional and personal } \\
\text { pressure that results from the nature of the investigations, dealing with } \\
\text { difficult people, demanding work conditions and continuous openness } \\
\text { to criticism from the courts and others. Is adaptable, uses humour, and } \\
\text { compartmentalises work separately from personal life. }\end{array}$ \\
\hline Tenacity & $\begin{array}{l}\text { Never gives up, patiently follows investigations through to the end } \\
\text { despite any obstacles, is inquisitive and leaves no stone unturned to } \\
\text { seek the truth. }\end{array}$ \\
\hline Teamwork & $\begin{array}{l}\text { Works well with others and fulfils their own role, regardless of how } \\
\text { big or small, to ensure team objectives are met. }\end{array}$ \\
\hline
\end{tabular}

[Insert Running title of $<72$ characters] 